\title{
Simulation of Time-Lapse Resistivity Method on Sandbox Model to Determine Fluid Changes and Desaturation
}

\author{
Rizka $^{1 *}$, Beta Arroma Piskora ${ }^{1}$, Soni Satiawan ${ }^{1}$, Hendra Saputra $^{2}$ \\ ${ }^{\prime}$ Department Geophysical Engineering, Institut Teknologi Sumatera, Lampung Selatan, Indonesia. \\ ${ }^{2}$ Department Geological Engineering, Institut Teknologi Sumatera, Lampung Selatan, Indonesia.
}

* Corresponding author : rizka@tg.itera.ac.id

Tel. : +628-1322-10-9961

Received: Dec 16, 2019; Accepted: Dec 18, 2020.

DOI 10.25299/jgeet.2020.5.4.4266

\begin{abstract}
Time-lapse resistivity method is an implementation of the resistivity method that is executed exactly at the same spot but with various in time. In this study, the technique uses to identify the dynamics of groundwater fluids. The application of the time-lapse resistivity method was carried out by performing a sandbox model simulation that contains layers of rocks with a fault structure. The rock layers consist of tuff, fine sandstone, shale, coarse sandstone, gravel that represents confined and unconfined aquifers. The simulation was achieved by applying the Electrical Resistivity Tomography (ERT) dipole-dipole configuration at the same place, and measurements with 3 different conditions, namely dry, wet conditions filled with $2.5 \%$ water and wet conditions filled with $5 \%$ water. Data acquisition uses Naniura resistivity meters with a track length of $96 \mathrm{~cm}$. The first measurement results (dry conditions) obtained a range of resistivity values from 3.7 to $168.1 \Omega$.m, the second measurement (wet conditions filled $2.5 \%$ water) obtained the range of resistivity values from 3.3 to $110.8 \Omega$.m and the third measurement (wet conditions) filled with $5 \%$ water the resistivity values range from 1.7 to $91.2 \Omega . \mathrm{m}$. Following the results of time-lapse inversion processing, a larger percentage change in the amount of $5.6 \%$ due to water absorption by the surface which then migrates into the inner layer. Whereas the percentage of desaturation ranges is from -3.11 to $0.217 \%$, refer to Archie's Law assumes conduction is caused by water content.
\end{abstract}

Keywords: Time-lapse resistivity, Electrical Resistivity Tomography, Sandbox model

\section{Introduction}

The geo-electric resistivity technique is a geo-electric technique that studies the electrical resistivity properties of rock layers in the earth. In this method, an electric current is injected into the earth through two current electrodes then the response is received through two potential electrodes. Based on the results of measurements of current and electric potential, variations in the resistivity value of the subsurface layer of the earth can be calculated. The difference in the variation in values obtained is the effect of different layers of the earth (Telford et al., 1990).

The geo-electrical methods used in this study are Electrical Resistivity Tomography (ERT) and time-lapse resistivity. ERT measurement is done by injecting electric current to the subsurface of the earth to obtain resistivity pseudo section or a distribution model of resistivity value of subsurface material laterally and vertically (Lowrie, 2007).

The concept of the time-lapse resistivity method is basically a measurement of repeated resistivity at the same location. The time-lapse resistivity method can be applied to observe subsurface changes caused by fluid movements (Williams et al., 2017), (Loke et al., 2018), (Kuswanto et al., 2018), (Pratama et al., 2018), (Comina et al., 2019), (Inim et al., 2020), (Rizka et al., 2020).

In this study, a time-lapse resistivity was implemented by making simulations (physical modeling) on an aquarium container (sandbox model) that contains layers of rock with a fault structure. The purpose of this simulation is to determine the resistivity value in rock samples, determine the change in fluid changes and desaturation to the resistivity values $(\rho)$, and to apply time-lapse resistivity inversion.

\section{Research Method}

The time-lapse resistivity method consists of several activities that can be simplified into data acquisition, data processing and, data interpretation. Data acquisition is done by making a model sandbox on an aquarium container made of glass with a length of $100 \mathrm{~cm}$, width $20 \mathrm{~cm}$, and a height of $13.5 \mathrm{~cm}$. The aquarium container is filled with five layers. From top to bottom are tuff, fine sandstone, clay, coarse sandstone, and gravel (Figure 1). Tuff is a sample from the outcrops of the Lampung Formation taken on the ITERA campus. Fine sandstone and clay are materials that have been sieved to obtain clean sandstone and clean clay. The fine sandstone is sand that passes sieve number 4 with a grain size of less than $4.75 \mathrm{~mm}$ and clay passed sieve number 100 with a grain size of less than $0.174 \mathrm{~mm}$. The rock layers are made to resemble a confined and unconfined aquifer which sandstone is an aquifer.

Measurement of time-lapse resistivity in the sandbox model was obtained using the Electrical Resistivity Tomography (ERT) method with dipole-dipole configuration. Physical measurement was conducted out under 3 conditions, namely dry condition (first condition) wet condition filled $2.5 \%$ water (second condition) and wet condition filled 5\% water (third condition). 


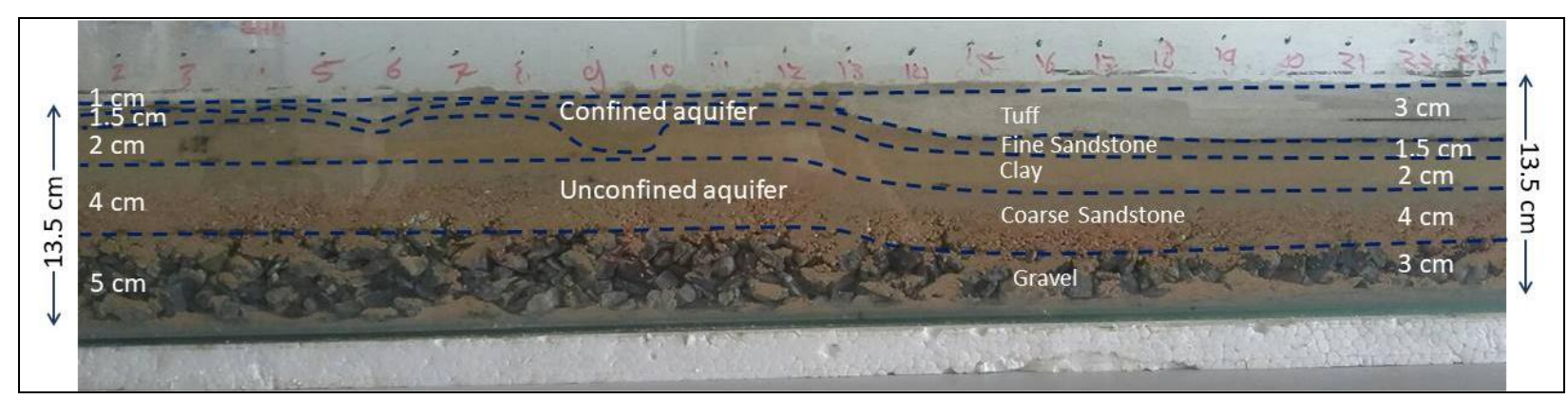

Fig. 1 Sandbox model

Measurements were made on rocks by sticking 4 nails that represent 4 electrodes $(\mathrm{C} 2, \mathrm{C} 1, \mathrm{P} 1$, and $\mathrm{P} 2)$. Furthermore, electrical current measurements $(\mathrm{C} 1$ and $\mathrm{C} 2)$ and potential difference (P1 and P2) are measured by dipole-dipole configuration using Naniura resistivity meters and multimeters. This configuration has another factor that represents the ratio of the distance between the electrodes $\mathrm{C} 1$ and P1, called $\mathrm{n}$ (Figure 2). The smallest space (a) is $4 \mathrm{~cm}$, the cross-section length is $96 \mathrm{~cm}$, the number of $\mathrm{n}$ is 14 and the number of datum points is 217 .

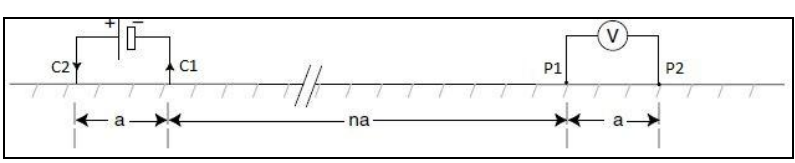

Fig 2. Dipole-dipole configuration (Everett, 2013)

Data processing was obtained based on the measurement results of the current value (I), potential difference (voltage, $\mathrm{V})$, and spacing (n). Then the geometry factor value is calculated using the equation

$\mathrm{K}=\mathrm{n}(\mathrm{n}+1)(\mathrm{n}+2) \pi \mathrm{a}$

so that the apparent resistivity value $\left(\rho_{a}\right)$ is obtained with the formula

$\rho_{\mathrm{a}}=\mathrm{K} \cdot \mathrm{R}$

Based on Ohm's law, resistance $(\mathrm{R})$ is calculated using the equation

$\mathrm{R}=\Delta \mathrm{V} / \mathrm{I}$

then

$\rho_{a}=\mathrm{K} \cdot \Delta \mathrm{V} / \mathrm{I}$ in

The result of pseudo resistivity calculation is made by inversion modeling to get the true resistivity value and the actual subsurface model. Then the time-lapse resistivity inversion was processed using Res2Dinv software to determine the change in the percentage of resistivity between the two sets of measurement data. Time-lapse data is used to show the presence of additional data sets according to time measurements. This is done by calculating the difference between the measurement of condition two and condition one (first data set) and calculated the difference between the measurement condition three and two (second data set). The parameters used in data processing in this study can be seen in Table 1.

Time-lapse inversion data processing uses the following parameters as follows:

- No constraints. In no constraints, the change in subsurface resistivity value is determined by comparing the model resistivity value obtained from the inversion of the initial data set and the next time dataset.
- Simultaneous inversion. In a simultaneous inversion, the first inversion or reference data set is followed by the inversion of the next time data set in each iteration. Because previously the authors chose "No constraints", the model obtained in the final iteration for the first data set is still used as the initial model for the next data set (Geotomo Software, 2010).

- First data set, the model for the first data set is used as a reference model for the second data set, while the model for the second data set is used as a reference model for the third data set, and similarly for other data sets (Geotomo Software, 2010).

- Display percentage change in resistivity is a display of changes in the resistivity model obtained from the inversion of the time set data then compared with the reference model from the first data set inversion (Geotomo Software, 2010).

Table 1. Parameter of processing

\begin{tabular}{ll}
\hline Parameter & Information \\
\hline Electrode array & Dipole-dipole \\
Number of electrodes & 4 \\
Number data points & 217 \\
Electrode spacing (a) & $4 \mathrm{~cm}$ \\
Separation factor (n) & 14 \\
Length of transect & $96 \mathrm{~cm}$ \\
Depth of investigation & $13.5 \mathrm{~cm}$ \\
Mesh Parameter & \\
Finite mesh grid size & 4 nodes \\
Mesh Parameter & Finite-Element Method \\
Mesh Refinement & Use normal mesh \\
Number of iterations & 7 \\
Select times lapse & No constraints \\
inversion constrain & Simultaneous inversion \\
& First data set \\
\hline
\end{tabular}

\section{Results and Discussion}

\subsection{Dry condition model sandbox (first condition)}

In this model, tuff rock, fine sandstone, clay, coarse sandstone, and gravel are used. Based on inversion modeling (Figure 3), it can be seen that the resistivity value of each rock layer in the range of 3.7-168.1 $\Omega . m$. Tuff has a resistivity value from 42.4 to $168.1 \Omega . \mathrm{m}$. Fine sandstone has a resistivity value from 14.5 to $68.8 \Omega$.m. Clay has a resistivity value from 3.7 to $36.1 \Omega . \mathrm{m}$. Coarse sandstone has a resistivity value from 4.5 to $14.8 \Omega$.m. Gravel rock has a resistivity value from 9.5 to $22.5 \Omega . \mathrm{m}$ 


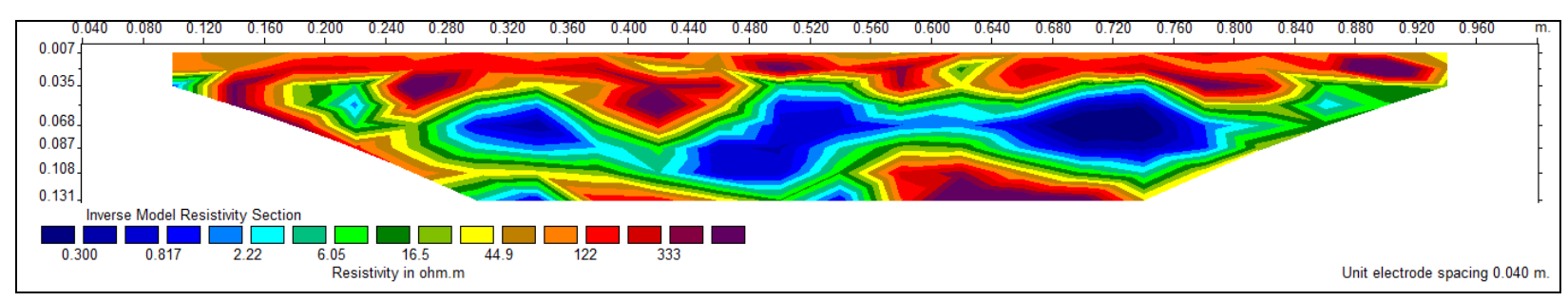

Fig 3. Pseudosection of resistivity models when dry condition

3.2. Wet condition model sandbox filled with $2.5 \%$ water (second condition)

The wet condition model sandbox filled with $2.5 \%$ (second condition) uses the same as the first condition. Based on inversion modeling (Figure 4), it can be seen that the resistivity value of each rock layer in the range of 3.3-110.8 $\Omega . \mathrm{m}$. Tuff has a resistivity value from 33.5 to $110.8 \Omega$.m. Fine sandstone has a resistivity value from 17.2 to $71.8 \Omega \mathrm{m}$. Clay has a resistivity value from 4.3 to $15.3 \Omega$.m. Coarse sandstone has a resistivity value from 3.5 to $13.0 \Omega$.m. Gravel rock has a resistivity value from 3.3 to $8.4 \Omega$.m.

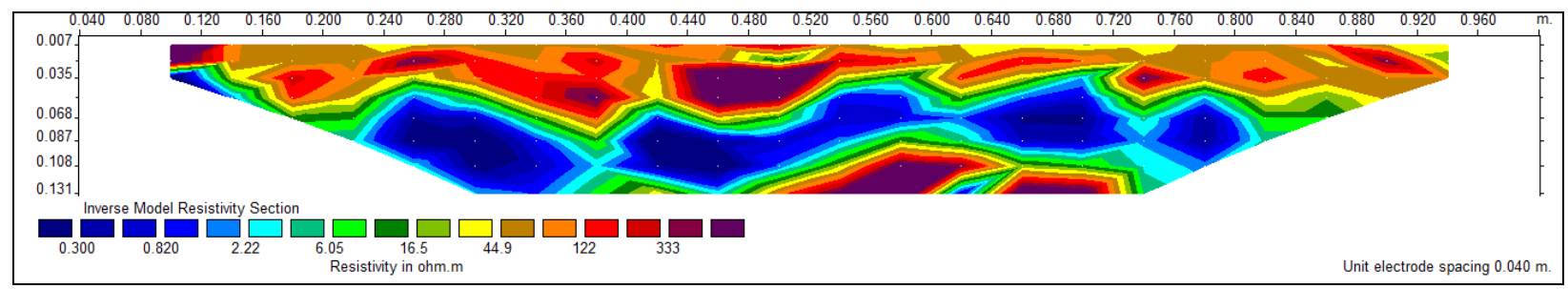

Fig 4. Pseudosection of resistivity models when wet condition model sandbox filled with $2.5 \%$ water

3.3. Wet condition model sandbox filled with $5 \%$ water (third condition)

The model used in the third condition is the same as the first and second conditions. However, in condition two it is filled with $5 \%$ of the water from the volume of the sandbox. Based on inversion modeling (Figure 5), it can be seen that the resistivity value of each rock layer in the range of 1.7-91.2 $\Omega . \mathrm{m}$. Tuff has a resistivity value from 29.7 to $91.2 \Omega$.m. Fine sandstone has a resistivity value from 14.8 to $54.7 \Omega$.m. Clay has a resistivity value from 3.7 to $22.9 \Omega . \mathrm{m}$. Coarse sandstone has a resistivity value from 2.6 to $17.3 \Omega$.m. Gravel has a resistivity value from 1.7 to $4.7 \Omega$.m.

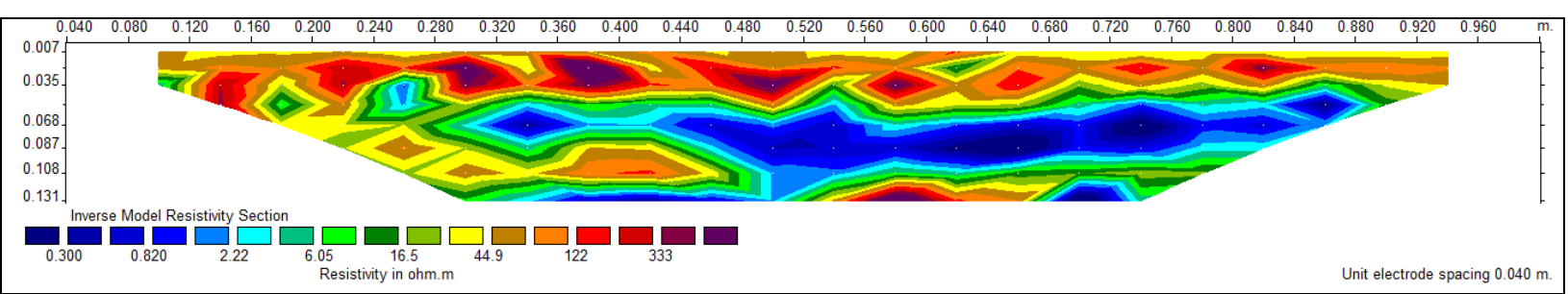

Fig 5. Pseudosection of resistivity model when wet condition model sandbox filled with $5 \%$ water

In the third condition is found a difference model with the previous condition because the rock sample has been filled with water which causes the rock resistivity to be small. Moreover, utility conditions of electrode changes, samples in the third condition most mobile due to utility displacement.

\subsection{Comparison of resistivity values from different conditions}

Based on experiments from first, second till third conditions, there is a difference in the true resistivity value which can be seen in Table 2. Based on the change in the true resistivity value, it can be seen that the true resistivity value gets smaller when the volume of water is added. So the resistance that the current passes through will be smaller. In Figure 6, there are three graphs of resistivity values where the blue graph (first condition) is the highest true resistivity value from the other conditions. The red graph (second condition) is moderate resistivity values from the other conditions. While the green graph (third condition) is the lowest resistivity value from the other conditions.

Table 2. Comparison of true resistivity values from different conditions

\begin{tabular}{|c|c|c|c|c|c|c|c|}
\hline \multirow[t]{2}{*}{ No. } & \multirow[t]{2}{*}{ Rocks } & \multicolumn{2}{|c|}{$\begin{array}{c}\text { Dry Condition (First } \\
\text { Condition) }\end{array}$} & \multicolumn{2}{|c|}{$\begin{array}{c}\text { Wet condition model sandbox } \\
\text { filled with } 2.5 \% \text { water (Second } \\
\text { Condition) }\end{array}$} & \multicolumn{2}{|c|}{$\begin{array}{l}\text { Wet condition model sandbox } \\
\text { filled with } 5 \% \text { water (Third } \\
\text { Condition) }\end{array}$} \\
\hline & & $\begin{array}{l}\text { Interval } \\
(\Omega \mathrm{m})\end{array}$ & $\begin{array}{l}\text { Average } \\
(\Omega \mathrm{m})\end{array}$ & Interval $(\Omega \mathrm{m})$ & Average $(\Omega \mathrm{m})$ & Interval $(\Omega \mathrm{m})$ & $\begin{array}{l}\text { Average } \\
(\Omega \mathrm{m})\end{array}$ \\
\hline 1 & Tuff & $42.4-168.1$ & 94.6 & $33.5-110.8$ & 68.5 & $29.7-91.2$ & 59 \\
\hline 2 & Fine sandstone & $14.5-68.8$ & 40.6 & $17.2-71.8$ & 36.3 & $14.8-54.7$ & 32.1 \\
\hline 5 & Gravel & $9.5-22.5$ & 13.3 & $3.3-8.4$ & 5.2 & $1.7-4.7$ & 3.4 \\
\hline
\end{tabular}




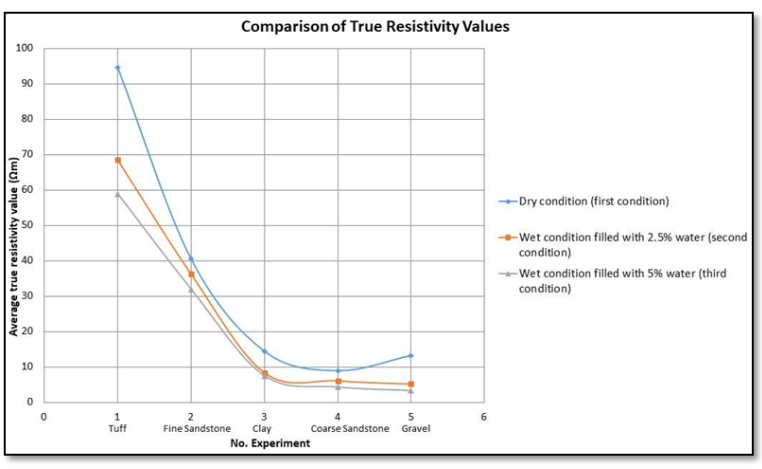

Fig 6. Graph of comparison true resistivity value from different conditions

The resistivity value is decrease influenced by the content of ions dissolved in water or electrolytic. Arrhenius (1884) definite ions are electrically charged atoms or molecules. They are either positively charged (cations) or negatively charged (anions). Arrhenius also noted the nature of electrolytes when dissolved in water, being to various degrees separated or dissociated into electrically opposing positive and negative ions. Based on this definition, acids are substances that ionize in aqueous solutions to produce hydrogen ions $\left(\mathrm{H}^{+}\right)$while alkali produce hydroxide ions $\left(\mathrm{OH}^{-}\right)$in solution (Heyrovska, 2011). So the chemical reaction of water $\left(\mathrm{H}_{2} \mathrm{O}\right)$ is as follows:

$$
\mathrm{H}_{2} \mathrm{O} \Leftrightarrow \mathrm{H}^{+}+\mathrm{OH}^{-}
$$

Based on the Arrhenius concept, water has acidic or alkaline. Because the two potentials are balanced, each ion has the same potential difference (voltage) value. The equation for the value of the potential difference causes the electric current flowing in the water to be zero so the water resistance value is infinite (Kurniawan et al., 2010) (Figure 7).

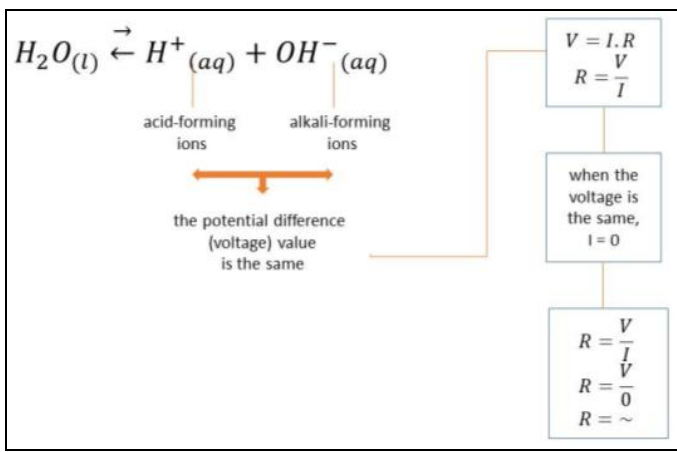

Fig 7. Flow chart of the relationship between the resistance value and the chemical composition of water (modified from Kurniawan et al. (2010))

\subsection{Time-lapse resistivity inversion modeling}

In this study, inversion modeling was also obtained using time-lapse resistivity inversion to see the percentage change in measurements of dry conditions (first condition), wet conditions filled with $2.5 \%$ water (second condition), and wet conditions filled with 5\% water (third condition). Data set changes were made twice, namely data set one (change in first and second condition) and data set two (change in second and third condition).

Based on the results of time-lapse inversion processing (Figure 8), the average change in resistivity for the two data sets is almost the same at all measurement points, except on the length $20-24 \mathrm{~cm}, 48-60 \mathrm{~cm}$, and $64-74 \mathrm{~cm}$, which shows a change in percentage about $5.6 \%$. This indicates a change in the resistivity value when measured under different conditions. This difference is due to the absorption of water by the surface which then migrates into the inner layer. Another cause is because the layer is more compact after being pressed during the measurement.

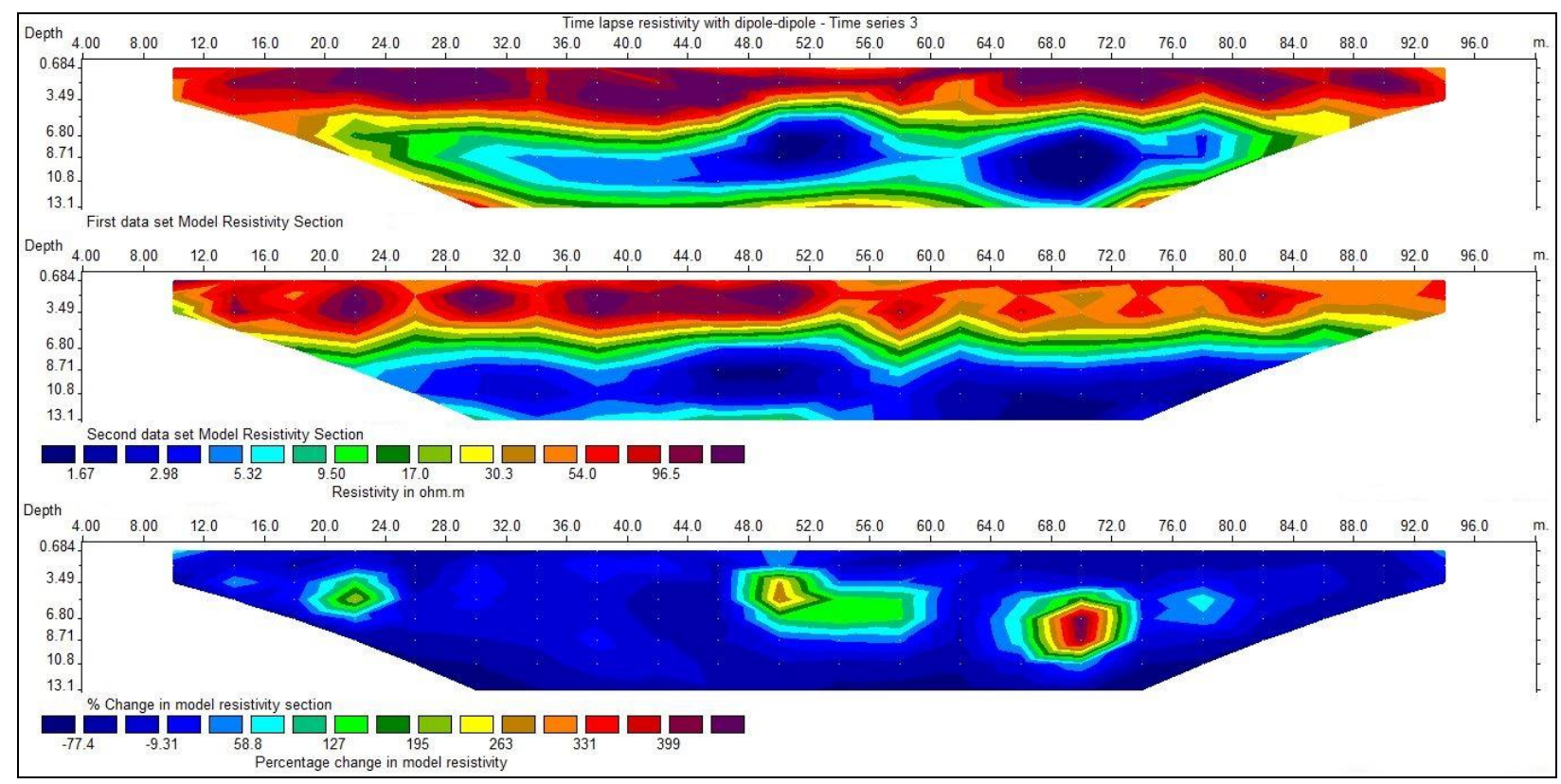

Fig 8. (top) first data set model resistivity section, (middle) second data set model resistivity section, (bottom) percentage change in model resistivity

In addition to producing a change in the percentage of resistivity, time-lapse inversion also produces a percentage of desaturation. Desaturation is a decrease in the level of water saturation in the aquifer (namely the reduction in the fraction per unit volume of rock filled with water) (Loke, 2004). Desaturation can be attributed to Archie's Law which provides that the relationship between the resistivity of porous rocks and the fluid saturation factor applies to certain types of rocks and sediments, especially those with low clay content. In this case, electrical conduction is assumed through the fluid that fills the pores of the stone. Archie's law is given by 


$$
\rho=a p_{W} \emptyset^{-m}
$$

where $\rho$ is the resistivity of the rock, $\rho_{\mathrm{w}}$ is the resistivity of the fluid, $\phi$ is the fraction of the rock filled with fluid, while a and $\mathrm{m}$. Under certain special conditions, the equations (6) can be used to determine the change in fluid saturation or fluid resistivity with time.
Based on Figure 9, it can be seen that the percentage value of desaturation shows an increase in the zone with a higher resistivity value with time due to water extraction. The decrease in the level of water saturation in the aquifer, or its desaturation value because Archie's Law assumes that conduction is due to water content.

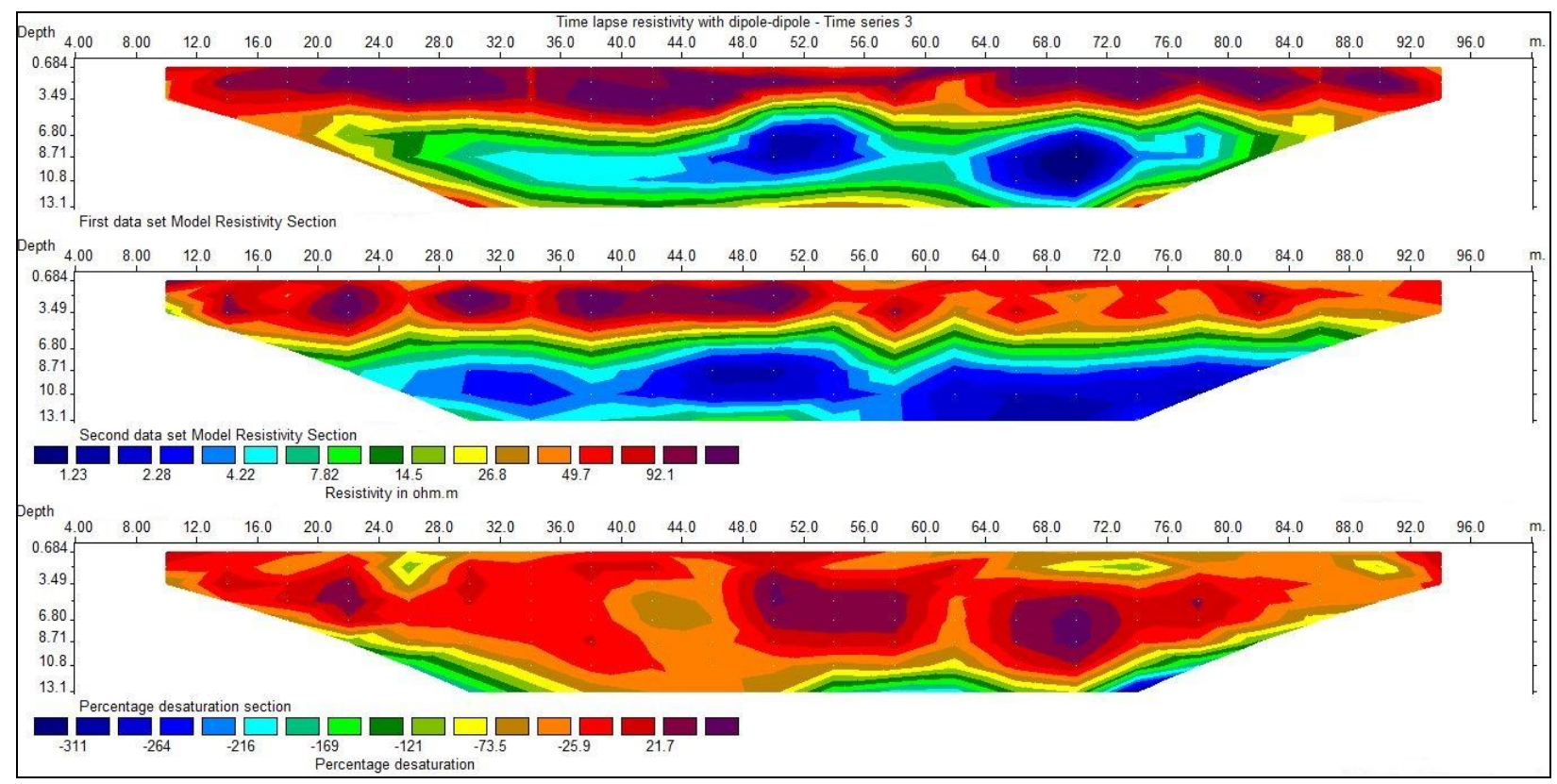

Fig 9. (top) first data set model resistivity section, (middle) second data set model resistivity section, (bottom) percentage desaturation

\section{Conclusion}

Time-lapse resistivity was obtained by making a simulation (physical modeling) on an aquarium container (sandbox model) which contains rock layers with a reverse fault structure, can find out the resistivity value in rock samples, determine fluid changes to the resistivity value $(\rho)$ and measure time-lapse resistivity inversion. Based on this research it can be concluded that:

1. There are some differences in the resistivity value from the first, second, and third conditions:

a) In dry conditions (first condition), tuff has a resistivity value from 42.4 to $168.1 \Omega$.m. Fine sandstone has a resistivity value from 14.5 to

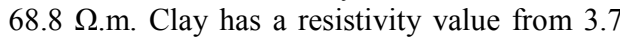
to $36.1 \Omega . \mathrm{m}$. Coarse sandstone has a resistivity value from 4.5 to $14.8 \Omega . \mathrm{m}$. Gravel rock has a resistivity value from 9.5 to $22.5 \Omega$.m.

b) In the $2.5 \%$ water filled condition (second condition), tuff has a resistivity value from 33.5 to $110.8 \Omega$.m. Fine sandstone has a resistivity value from 17.2 to $71.8 \Omega . \mathrm{m}$. Clay has a resistivity value from 4.3 to $15.3 \Omega$.m. Coarse sandstone has a resistivity value from 3.5 to 13.0 $\Omega . \mathrm{m}$. Gravel rock has a resistivity value from 3.3 to $8.4 \Omega . \mathrm{m}$.

c) In the $5 \%$ water filled from the volume of sandbox (third condition), tuff has a resistivity value from 29.7 to $91.2 \Omega$.m. Fine sandstone has a resistivity value from 14.8 to $54.7 \Omega$.m. Clay has a resistivity value from 3.7 to $22.9 \Omega$.m. Coarse sandstone has a resistivity value from 2.6 to $17.3 \Omega$.m. Gravel has a resistivity value from 1.7 to $4.7 \Omega . \mathrm{m}$.

2. The decrease in the resistivity value of each layer occurs due to the increase in the amount of water contained in each layer. The more water in the layer, the more electrolyte ions will be, so that the electric current that is injected will be easily flowed by the electrolyte ions. The electric current flows through a material either conductor or semiconductor that is able to conduct electric current properly.

3. Based on the results of time-lapse inversion processing shows:

- The percentage change is greater, namely $5.6 \%$. This difference is due to the absorption of water by the surface which then migrates into the inner layer. Another reason because the layer is more compact after being pressed during the measurement.

- Percentage of desaturation that shows an increase in the zone with a higher resistivity value with time due to water extraction. A decrease in the level of water saturation in the aquifer or its desaturation value because Archie's Law assumes that conduction is caused by water content.

\section{Acknowledgment}

We want to thank the Director of Research and Community Service at the Ministry of Research, Technology, and Higher with contract number 009/SP2H/LT/DRPM/2018 for providing the funding and also to geophysical engineering ITERA students to assist with acquisition data.

\section{References}

Comina, C., Giordano, N., Ghidone, G., Fischanger, F., 2019. Time-lapse 3D electric tomography for short-time monitoring of an experimental heat storage system. Geosci. 9. https://doi.org/10.3390/geosciences9040167

Everett, M.E., 2013. Near-Surface Applied Geophysics, First. ed. Cambridge University Press, New York.

Geotomo Software, 2010. RES2DINV ver. 3.59 - Rapid 2-D Resistivity \& IP inversion using the least-squares 
method Wenner $(\rho, \rho, \rho)$, dipole-dipole, inline pole-pole, pole- dipole, equatorial dipole-dipole, offset poledipole, Wenner-Schlumberger, gradient and nonconventional arrays.

Heyrovska, R., 2011. Partial Dissociation and Hydration Quantitatively Explain the Properties of Aqueous Electrolyte Solutions and hence Empirical Activity Concepts are Unnecessary. Nat. Preced. 1-21. https://doi.org/10.1038/npre.2011.6416.1

Inim, I.J., Udosen, N.I., Tijani, M.N., Affiah, U.E., George, N.J., 2020. Time-lapse electrical resistivity investigation of seawater intrusion in coastal aquifer of Ibeno, Southeastern Nigeria. Appl. Water Sci. 10, 1-12. https://doi.org/10.1007/s13201-020-01316-x

Kurniawan, A., Tri Nugroho, A., Hermawan, A., Bagus Ari P, Y., Aryo Wibowo, D., Nahara S, Q., H, Nova, H., Darumaya, 2010. Identifikasi Kualitas Air Berdasarkan Nilai Resistivitas Air. Masy. Ilmu Bumi Indones. 1, 15.

Kuswanto, A., Garinas, W., Zikri, S., 2018. Proses Pengambilan Data Dan Pemanfaatan Geolistrik Metoda 4-D Untuk Pemetaan Geologi Bawah Permukaan. Maj. Ilm. Pengkaj. Ind. 12, 47 https://doi.org/10.29122/mipi.v12i1.501

Loke, M.H., 2004. Tutorial: 2-D and 3-D Electrical Imaging Surveys 136.

Loke, M.H., Wilkinson, P.B., Dahlin, T., Chambers, J.E., Uhlemann, S., Dijkstra, T., 2018. Time-lapse 4-D resistivity imaging inversion with positivity constraints, in: 24th European Meeting of Environmental and Engineering Geophysics. https://doi.org/10.3997/22144609.201802625

Lowrie, W., 2007. Fundamentals of Geophysics, Fundamentals of Geophysics. https://doi.org/10.1017/cbo9780511807107

Pratama, R.K., Akmam, Mahrizal, 2018. Identifikasi Prekursor Tanah Longsor Berdasarkan Perubahan Nilai Tahanan Jenis Batuan Menggunakan Metode Geolistrik TimeLapse Konfigurasi Dipole-Dipole di Bukik Lantiak Kecamatan Padang Selatan. Pillar Phys. 11, 41-48.

Rizka, Satiawan, S., Saputra, H., 2020. Application 4D Resistivity Method for Determining Effect of Water Content; Case Study ITERA Campus, in: IOP Conference Series: Earth and Environmental Science. pp. 4-8. https://doi.org/10.1088/1755$1315 / 537 / 1 / 012012$

Telford, W.M., Geldart, L.P., Sheriff, R.E., 1990. Applied Geophysics. Cambridge University Press.

Williams, M.R., Buda, A.R., Singha, K., Folmar, G.J., Elliott, H.A., Schmidt, J.P., 2017. Imaging Hydrological Processes in Headwater Riparian Seeps with TimeLapse Electrical Resistivity. Groundwater 55, 136-148. https://doi.org/10.1111/gwat.12461

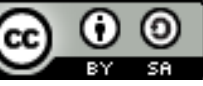

(C) 2020 Journal of Geoscience, Engineering, Environment and Technology. All rights reserved. This is an open access article distributed under the terms of the CC BY-SA License (http://creativecommons.org/licenses/by$\mathrm{sa} / 4.0 /)$. 